Jurnal

Kardiologi Indonesia

J Kardiol Indones. 2013;34:154-9

ISSN 0I26/3773

Clinical Research

\title{
Opportunistic Screening for The Detection of Newly Diagnosed Diabetes Melitus
}

\author{
Sri R Paputungan, Fabiola MS Adam, John MF Adam
}

Sub-Division of Endocrinology and Metabolism, Department of Internal Medicine,

Faculty of Medicine, Hasanuddin

University, Makassar
Background. It is estimated that $50 \%$ of the diabetic patients are undiagnosed. Opportunistic screening is one of the screening method, to detect newly diagnosed diabetes mellitus. The aim of this study is to detect the undiagnosed diabetes mellitus by screening in the clinical setting.

Subjects and Methods. Subjects were form the EIDEG screening for diabetes mellitus. The procedure is a two step screening, first using the reflectance meter for capillary blood sugar, followed by confirmation test in the laboratory. Capillary blood sugar was divided into 3 groups, $<100$ $\mathrm{mg} / \mathrm{dL}$ as normal, $100-199 \mathrm{mg} / \mathrm{dl}$ possible diabetes, and $\geq 200 \mathrm{mg} / \mathrm{dL}$ suspected diabetes. For group two, an OGTT was performed, and for group three, only FPG. Diabetes mellitus was diagnosed if FPG $\geq 126 \mathrm{mg} / \mathrm{dl}$ and or 2 hour OGTT $\geq 200 \mathrm{mg} / \mathrm{dl}$.

Results. During the screening, 4737 subjects can be screened, only I654 completed the screening. Diabetes mellitus was diagnosed in 240 subjects or $14.5 \%$. There were more females compared to males, $52,9 \%$ and $47,1 \%$ subsequently, most were at the age $\geq 50$ years. More diabetic patients were diagnosed by OGTT compared to FPG only.

Conclusions. This study showed that opportunistic screening may detect more diabetic patients. It is suggested that this screening procedure can be used by every clinicians in their daily practice.

(J Kardiol Indones. 2013;34:154-9)

Keywords: opportunistic screening, diabetes mellitus 


\title{
Skrining Oportunistik untuk Mendeteksi Diabetes Melitus yang Baru Terdiagnosis
}

\author{
Sri R Paputungan, Fabiola MS Adam, John MF Adam
}

\begin{abstract}
Latar belakang. Diperkirakan sekitar 50\% dari penderita diabetes melitus tidak terdiagnsis. Skrining oportunistik merupakan salah satu cara skrining untuk menemukan diabetes melitus yang belum terdiagnosis. Tujuan penelitian ini adalah untuk mendeteksi penderita diabetes melitus baru terdiagnosis di klinik.

Subyek dan metoda. Subyek berasal dari program skrining oleh East Indonesia Diabetes Epidemiology Group. Cara skrining yang digunakan adalah cara dua tahap. Tahap pertama dengan menggunakan reflectance meter untuk pemeriksaan glukosa darah kapiler, kemudian dilanjutkan dengan tes konfirmasi di laboratorium. Glukosa darah kapiler dibagi atas 3 kelompok, $<100 \mathrm{mg} / \mathrm{dL}$ normal, $100-199 \mathrm{mg} / \mathrm{dl}$ mungkin diabetes melitus, dan $\geq 200 \mathrm{mg} / \mathrm{dL}$ curiga diabetes melitus. Untuk kelompok kedua dilanjutkan dengan tes TTGO, sedang kelompok ketiga hanya dilakukan pemeriksaan glukosa plasma puasa. Diabetes melitus didiagnosis apabila glukosa puasa $\geq 126 \mathrm{mg} / \mathrm{dl}$ dan / atau 2 jam TTGO $\geq 200 \mathrm{mg} / \mathrm{dl}$.

Hasil. Selama skrining dapat diperiksa sebanyak 4737 subyek, tetapi hanya 1654 orang melengkapi pemeriksaan. Dari jumlah tersebut, 240 subyek terdiagnosis sebagai diabetes melitus atau 14.5\%. Lebih banyak wanita dibandingkan pria yaitu masingmasing $52,9 \%$ dan $47,1 \%$, penderita terbanyak pada usia $\geq 50$ tahun. Lebih banyak penderita terdiagnosis dengan pemeriksaan TTGO dibandingkan dengan kadar glukosa plasma puasa saja.

Kesimpulan. Penelitian ini menunjukkan bahwa skrining oportunistik dapat mendeteksi cukup banyak penderita diabetes baru. Dianjurkan cara skrining ini dapat dilakukan di klinik oleh para dokter praktek.
\end{abstract}

(J Kardiol Indones. 2012;33:154-9)

Kata kunci: skrining oportunistik, diabetes melitus

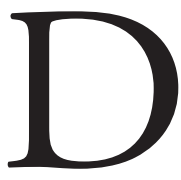
alam tiga dekade terakhir diabetes melitus tumbuh dengan pesat hampir diseluruh dunia khususnya di negara Asia termasuk Indonesia. Di tahun 1980an prevalensi diabetes melitus di beberapa propinsi di Indonesia seperti Jakarta, ${ }^{1}$ Semarang ${ }^{2}$ dan Makassar ${ }^{3}$ hanya sekitar $1.5 \%$. Pada tahun 2000an, prevalensi diabetes melitus

\section{Alamat Korespondensi}

dr. John MF Adam. Sub Bagian Endokrin Metabolik, Bagian Ilmu Penyakit Dalam, Fakultas Kedokteran, Universitas Hasanuddin Makassar. E-mail: john_mfadam@yahoo.com meningkat dengan pesat, di Jakarta $14.2 \%,{ }^{4}$ Makassar $^{5}$ 9.1\% dan di Bali 5.9\%. ${ }^{6}$ Sebagian besar dari penderita diabetes melitus tipe 2 tidak mempunyai keluhan, sehingga pada tahap dini sulit untuk terdeteksi. Pada umumnya diabetes melitus tipe 2 baru terdiagnosis setelah 5-12 tahun menderita hiperglikemi. ${ }^{7}$

Pada saat ini diperkirakan hanya sekitar 50\% dari penderita diabetes melitus yang terdeteksi, sisanya lagi tidak terdiagnosis. Oleh karena itu deteksi dini dan sekaligus penatalaksanaan yang agresif merupakan cara yang terbaik untuk mencegah komplikasi kronik diabetes melitus. Sampai saat ini belum ada 
kesepakatan mengenai cara skrining yang terbaik. Pada dasarnya ada dua cara skrining yaitu skrining pada populasi (community screening) dan skrining di klinik (opportunistic screening $=$ clinical setting). ${ }^{6}$ Skrining di klinik, bertujuan untuk mendeteksi penderita diabetes melitus sebanyak mungkin agar segera dapat diberikan pengobatan. Cara skrining ini dapat dilakukan oleh dokter atau tenaga kesehatan lainnya, yang dilakukan baik di tempat praktek pribadi, atau di klinik rumah sakit.

Skrining diabetes melitus di klinik dapat dilakukan dengan cara skrining satu tahap, yaitu hanya dengan pemeriksaan glukosa plasma puasa (GPP) seperti yang dianjurkan oleh American Diabetes Associatiiom (ADA 2010). ${ }^{8}$ Banyak peneliti lebih cenderung untuk melakukan skrining diabetes melitus dua tahap yaitu selain pemeriksaan puasa harus dilengkap dengan pemeriksaan tes toleransi glukosa oral (TTGO). Untuk diagnosis diabetes melitus cara yang baku adalah kadar glukosa plasma baik puasa maupun TTGO. Sejak lama sudah diperkenalkan alat refelctance meter yang dapat memeriksa glukosa darah perifer dengan mudah. Sejak tahun 2003, East Indonesia Diabetes Epidemiology Group (EIDEG) telah melakukan cara skrining dua tahap dengan menggunakan reflectance meter sebagai tahap pertama dengan hasil yang cukup memuaskan. Pada makalah ini dilaporkan hasil penelitian skrining oportunistik dengan cara dua tahap.

\section{Subjek dan Cara Kerja}

Penelitian ini adalah penelitian deskriptif. Subjek yang diteliti berasal dari pengunjung kilinik pribadi atau klinik rumah sakit dari dokter yang ikut serta pada penelitian EIDEG. Subyek yang dilakukan skrining adalah mereka yang berisiko tinggi menjadi diabetes melitus yaitu umur $\geq 45$ tahun, riwayat keluarga (orang tua) diabetes melitus, hipertensi, obes yaitu indeks massa tubuh (IMT) $\geq 25 \mathrm{~kg} / \mathrm{m}^{2}$, dan untuk wanita mereka mempunyai riwayat pernah melahirkan bayi besar $\geq 4 \mathrm{~kg} .{ }^{8}$

Pada tahap pertama pemeriksaan glukosa darah sewaktu dilakukan dengan menggunakan alat Reflectance Meter dengan contoh darah kapiler. Kadar glukosa darah perifer dibagi atas tiga kelompok yaitu a) glukosa darah $<100 \mathrm{mg} / \mathrm{dL}$ dinilai normal, b) $100-200$ $\mathrm{mg} / \mathrm{dL}$ mungkin diabetes melitus, dan $\geq 200 \mathrm{mg} / \mathrm{dL}$ sangat mencurigakan. Pada mereka yang kelompok kedua 100-200 mg/dL dilanjutkan dengan pemeriksaan TTGO, dan yang kelompok tiga $\geq 200 \mathrm{mg} / \mathrm{dL}$ cukup dengan pemeriksaan GPP. Baik pemeriksaan GPP maupun TTGO dilakukan di laboratorium menggunakan contoh darah plasma vena, dengan cara kimia klinik yaitu GOD-PAP. Dinyatakan diabetes melitus bila GPP $\geq 126 \mathrm{mg} / \mathrm{dL}$ dan/atau 2 jam setelah TTGO $\geq 200 \mathrm{mg} / \mathrm{dL}$ (gambar 1).

Pada penelitian ini faktor risiko kejadian diabetes melitus hanya dibatasi pada usia $\geq 45$ tahun, IMT $\geq 25 \mathrm{~kg} / \mathrm{m}^{2}$, hipertensi (tekanan darah $\geq 140 \mathrm{mmHg}$ / $90 \mathrm{mmHg}$ ), kadar trigliserida $\geq 150 \mathrm{mg} / \mathrm{dL}$, kadar kolesterol-total, kolestrol-LDL, dan kadar kolestrolHDL $<40 \mathrm{mg} / \mathrm{dL}$, Analisis data dilakukan dengan menggunakan SPSS versi 17. Metode statistik diskriptif yang digunakan adalah perhitungan nilai rerata dan simpang baku. Untuk uji statistik digunakan multiple logistic regression test. Hasil uji dianggap bermakna bila nilai $\mathrm{p}<0,05$.

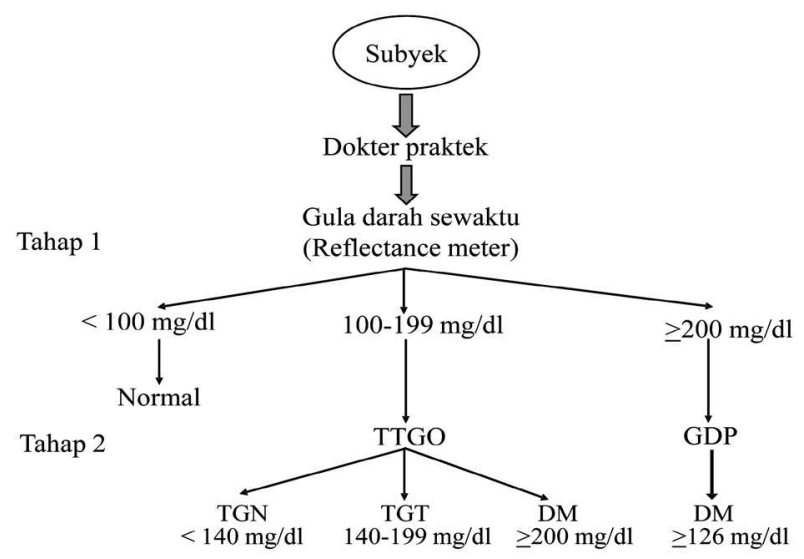

Gambar 1. Cara skrining diabetes melitus dua thap menurut EIDEG

$\mathrm{TGN}=$ toleransi glukosa normal, $\mathrm{TGT}=$ toleransi glukosa terganggu, $\mathrm{DM}=$ diabetes melitus

\section{Hasil Penelitian}

Sejak tahun 2003 sampai Desember 2011, sebanyak 4737 subjek pengunjung klinik yang didapatkan dari tahap pertama (glukosa darah kapiler). Dari jumlah tersebut hanya 1654 orang yang melanjutkan pemeriksaan tahap dua mereka terdiri atas wanita $888(53.7 \%)$ dan pria 766 (46.3\%). Alasan tidak melanjutkan pemeriksaan ke tahap kedua bermacammacam, antara lain tidak datang ke laboratorium, takut diambil darah vena, muntah setelah minum glukosa. Karakteristik subyek yang diteliti dapat dilihat pada table 1. 
Tabel 1. Karakteristik dari 1654 subyek yang diteliti

\begin{tabular}{lc}
\hline Karakteristik & $\begin{array}{c}1645 \text { subyek yang diteliti } \\
(\text { Mean } \pm \text { SD) }\end{array}$ \\
\hline Umur & $48,7 \pm 10,8$ \\
IMT & $26.5 \pm 4,5$ \\
TDS & $131,7 \pm 24,1$ \\
TDD & $83,7 \pm 12,6$ \\
Kol-total & $216,4 \pm 44,0$ \\
LDL-kol & $139,1 \pm 40,6$ \\
HDL-kol & $46,2 \pm 15,1$ \\
TG & $149,7 \pm 82,6$ \\
\hline
\end{tabular}

yang terdiagnosis dengan pemeriksaaan TTGO.

Hasil analisis multivariat (regresi logistik) terhadap variabel risiko diabetes melitus yang berhubungan dengan kadar GPP $\geq 126 \mathrm{mg} / \mathrm{dl}$, hanya usia $\geq 45$ tahun dan kolesterol-total $\geq 200 \mathrm{mg} / \mathrm{dL}$ yang secara statistik mempunyai hubungan yang bermakna ( $\mathrm{p}$ $<0,05$ ). Mereka yang berusia $\geq 45$ tahun mempunyai risiko menjadi diabetes melitus sebesar 1,7 kali, sedang untuk kadar kolesterol-LDL total $\geq 200$ risiko menjadi diabetes melitus sebesar 1,8 kali. Untuk diagnosis diabetes mellitus berdasarkan TTGO $\geq 200 \mathrm{mg} / \mathrm{dL}$ selain usia $\geq 45$ tahun juga IMT $\geq 25 \mathrm{~kg} / \mathrm{m}^{2}$ secara

Tabel 2. Prevalensi diabetes melitus pada pria dan wanita menurut kelompok umur

\begin{tabular}{|c|c|c|c|c|c|c|c|c|c|}
\hline \multirow{3}{*}{$\begin{array}{l}\text { Subyek yang diteliti } \\
\text { (umur) }\end{array}$} & \multicolumn{3}{|c|}{ Pria } & \multicolumn{3}{|c|}{ Wanita } & \multicolumn{3}{|c|}{ Total } \\
\hline & \multirow{2}{*}{ Subyek } & \multicolumn{2}{|c|}{ DM } & \multirow{2}{*}{ Subyek } & \multicolumn{2}{|c|}{$\mathrm{DM}$} & \multirow[b]{2}{*}{ Subyek } & \multicolumn{2}{|c|}{ DM } \\
\hline & & $\mathrm{n}$ & $\%$ & & $\mathrm{n}$ & $\%$ & & $\mathrm{n}$ & $\%$ \\
\hline $30-39$ & 151 & 15 & 9,9 & 172 & 19 & 11 & 323 & 34 & 10,5 \\
\hline $40-49$ & 279 & 37 & 13,3 & 334 & 36 & 10,8 & 613 & 73 & 11,9 \\
\hline $50-59$ & 223 & 44 & 19,7 & 226 & 40 & 17,7 & 449 & 84 & 18,7 \\
\hline $60-69$ & 88 & 13 & 14,8 & 125 & 27 & 21,6 & 213 & 40 & 18,8 \\
\hline$\geq 70$ & 25 & 4 & 16,0 & 31 & 5 & 16,1 & 56 & 9 & 16,1 \\
\hline Total & 766 & 113 & 14,8 & 888 & 127 & 14,3 & 1654 & 240 & 14,5 \\
\hline
\end{tabular}

$\mathrm{DM}=$ diabetes mellitus

Variabel dalam table 1 kemudian dikelompokkan sbb: usia $\geq 45$ tahun dan $<45$ tahun, IMT $\geq 25 \mathrm{~kg} /$ $\mathrm{m}^{2}$ dan $<25 \mathrm{~kg} / \mathrm{m}^{2}$, tekanan darah dikelompokkan $\geq 140 / 90 \mathrm{mmHg}$ dan $<140 / 90 \mathrm{mmHg}$, kadar kolesterol-total $\geq 200 \mathrm{mg} / \mathrm{dL}$ dan $<200 \mathrm{mg} / \mathrm{dL}$, kolesterol HDL $<40 \mathrm{mg} / \mathrm{dL}$ dan $\geq 40 \mathrm{mg} / \mathrm{dL}$, dan kadar trigliserida $\geq 150 \mathrm{mg} / \mathrm{dl}$, dan $<150 \mathrm{mg} / \mathrm{dl}$.

Pada penelitian ini dapat terjaring penderita diabetes melitus sebanyak 240 subyek atau suatu prevalensi sebesar $14.5 \%$, pada pria $47.1 \%$ dan wanita $52,9 \%$ perbedaan tersebut tidak bermakna $(\mathrm{p}=0,795)$. Pada tabel 2 dapat dilihat bahwa jumlah penderita diabetes melitus berusia $\geq 50$ tahun lebih banyak dibandingkan dengan mereka yang berusia $<50$ tahun, yaitu masing-masing $18,5 \%$ dan $11,4 \%$, secara statistik perbedaan ini bermakna $(\mathrm{p}<0,001)$

Dari 240 penderita diabetes melitus yang terdiagnosis sebagian besar terdeteksi dengan TTGO, yaitu 159 penderita atau $66,3 \%, 21$ penderita atau $8.8 \%$ dengan GPP $(\geq 126 \mathrm{mg} / \mathrm{dL})$, dan sisanya 60 penderita atau $25.0 \%$ dengan GPP dan TTGO $(\geq 126$ $\mathrm{mg} / \mathrm{dL}$ dan $\geq 200 \mathrm{mg} / \mathrm{dL}$ ) (gambar 1 ). Dari hasil diagnosis ini nampak bahwa lebih banyak penderita statistik bermakna untuk kejadian diabetes melitus $(\mathrm{p}<0.001$ dan $\mathrm{p}<0.05)$. Mereka yang berusia $\geq 45$ tahun mempunyai risiko menjadi diabetes melitus sebesar 1.8 kali, sedang yang kolesterol total $\geq 200$ $\mathrm{mg} / \mathrm{dl} 1.4$ kali lebih besar. Untuk diagnosis diabetes

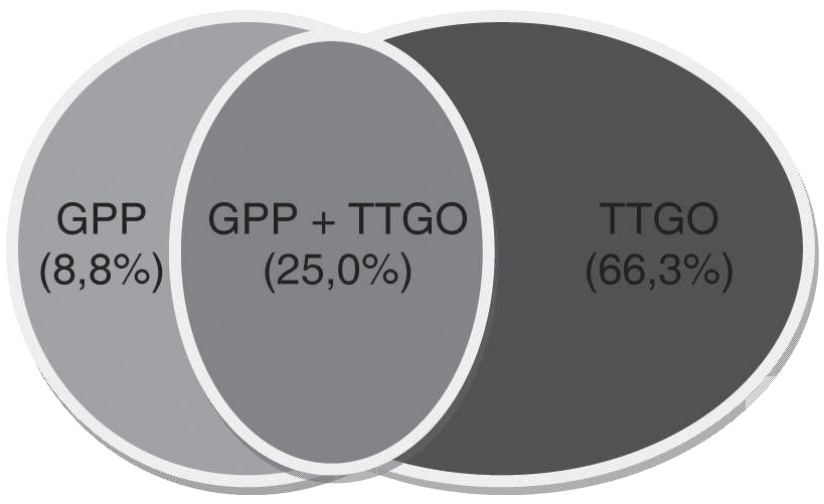

Gambar 1. Persentasi penderita diabetes melitus berdasarkan kriteria diagnosis diabetes mellitus.

$\mathrm{GPP}=$ glukosa plasma puasa, $\mathrm{TTGO}=$ tes toleransi glukosa oral 
melitus berdasarkan GPP $\geq 126 \mathrm{mg} / \mathrm{dL}$ dan TTGO $\geq 200 \mathrm{mg} / \mathrm{dL}$ hanya usia $\geq 45$ tahun yang bermakna ( $\mathrm{p}<0.001)$ meningkatkan diabetes melitus dengan risiko kemungkinan menjadi diabetes melitus sebesar 2.1 kali. Dengan demikian bila digabungkan ketiga kriteria diagnosis diabetes melitus hanya umur yang berperan.

\section{Pembahasan}

Pada penelitian ini terjaring sebanyak 240 penderita dibetes melitus baru dari 1654 subjek yang diperiksa atau prevalensi sebesar 14.5\%. Apabila dibandingkan dengan penelitian yang serupa di negara maju, hasil penelitian ini jumlah prevalensi diabetes melitus jauh lebih tinggi. Diabetes Screening in Canada (DIASCAN) study pada tahun 2001, ${ }^{9}$ menggunakan dokter keluarga untuk melakukan skrining pada penduduk dewasa. Pada penelitian ini sebanyak 9564 subyek yang dilakukan skrining, hanya menemukan diabetes melitus sebesar 2.2\%. Cogneau dkk di Perancis ${ }^{10}$ melakukan penelitian yang hampir sama dan menjaring 5950 subyek risiko tinggi. Hasil penelitian ini prevalensi diabetes melitus sebanyak $2.7 \%$, sebagian besar adalah yang berusia $\geq 40$ tahun. Penelitian di Australia oleh Welborn $\mathrm{dkk}^{11}$ yang juga melibatkan dokter keluarga melibatkan sebanyak 50.859 subyek. Pada penelitian tersebut prevalensi diabetes melitus $2.0 \%$. Dari data diatas terlihat bahwa hasil penelitian skrining oportunistik di luar negeri menemukan prevalensi diabetes melitus yang lebih rendah. Hal ini mungkin oleh karena di negara maju skrining untuk mendeteksi penderita diabetes melitus baru dilakukan secara berkala. American Diabetes Association ${ }^{12}$ menganjurkan pemeriksaan berkala harus dilaukan setiap tiga tahun bagi mereka yag hasil skrining sebelumnya normal. Penelitian Ramachandran $\mathrm{dkk}^{12}$ di India, dari sebanyak 1000 penderita diabetes melitus yang ditemukan dengan skrining oportunistik $71 \%$ adalah mereka yang tanpa keluhan diabetes melitus, angka ini jauh lebih tiggi dibandingkan penelitian kami. Perlu diketahui bahwa India merupakan negara dengan prevalensi diabetes melitus tertinggi di bunia.

Pada penelitian ini mendapatkan bahwa apabila skrining diabetes melitus hanya dilakukan dengan pemeriksaan GPP saja maka sebagian besar penderita diabetes melitus akan tidak terdiagnosis, oleh karena itu skrining oportunistik disarankan agar lengkap dengan pemeriksaan TTGO. Penelitian Diabetes Epidemiology: Collaboratiev Analysis of Diagnostic Criteria in Europe (DECODE) di Eropa juga merekomendasikan untuk melakukan skrining diabetes melitus pemeriksaan TTGO harus dilakukan terutama pada mereka dengan usia usia lanjut. ${ }^{13}$ Dari beberapa faktor risiko yang dipakai pada penelitian ini baik untuk mendeteksi diabetes melitus dengan GPP, GPP dan TTGO, atau hanya TTGO saja terlihat faktor usia yaitu $\geq 45$ tahun berperan sangat penting. Hal ini sama dengan yang dianjurkan oleh ADA bahwa semua subyek $\geq 45$ tahun harus dianggap sebagai risiko tinggi dan secara berkala harus dilakukan pemeriksaan skrining diabetes melitus melitus setiap tiga tahun. ${ }^{8}$

Mengingat pengunjung klinik adalah penderita yang datang untuk berobat maka pemeriksaan glukosa darah kapiler sewaktu sangat mudah diterima oleh penderita. Walaupun demikian masih menjadi hambatan untuk skrining oportunistik adalah menganjurkan mereka ke laborotorium untuk pemeriksaan tes konfirmasi yang harus menggunakan darah vena. Pada penelitian ini dapat dilihat bahwa sebagian besar subyek yang dilakukan pemeriksaan glukosa darah dengan reflectance meter di klinik tidak melanjutkan pemeriksaan ke laboratorium. Kekurangan dari penelitian ini bahwa sejak awal tidak disiapkan kuesioner yang lengkap, secara khusus untuk faktor risiko diabetes melitus sehingga tidak dapat mendata faktor risiko secara lengkap. Selain itu oleh karena biaya yang terbatas maka pemeriksaan di laboratorium sebagian harus dibiayai oleh penderita sendiri.

Dari penelitian ini dapat disimpulkan bahwa cara skrining oportunistik dua tahap sangat berfaedah untuk menjaring penderita diabetes melitus baru di klinik. Perlu dilakukan penelitian lebih lanjut dengan persiapan yang lebih baik dan mengikut sertakan dokter yang lebih banyak untuk menjaring subyek diabetes melitus yang lebih besar.

\section{Ucapan Terima Kasih}

Peneliti mengucapkan terima kasih kepada Dr. dr. Arifin Seweng yang telah membantu menganalisa statistk peneitian ini. Kepada Laboratorium Prodia yang telah membantu sebagian dari biaya penelitian, dan kepada sdri. Lili Linggar yang membantu menyusun data hasil penelitian dan mengetik makalah ini. 


\section{Daftar Pustaka}

1. Waspadji S, Ranakusuma AB, Sujono S, Supartondo, Sukaton U. Diabetes mellitus in an urban population in Jakarta. Acta medica Indonesian XIV: 123-130, 1983.

2. Soetardjo, Moeljanto R. Diabetes Melitus di Kelurahan Pekajangan - Pekalongan. Naskah Lengkap Kongres Nasional Ahli Penyakit Dalam (KOPAPDI V Bagian Ilmu Penyakit Dalam Fakultas Kedokteran Universitas Diponegoro - RS Dr. Kariadi, Semarang. 99-105:1981.

3. Adam JMF. Survey diabetes mellitus pada sekelompok penduduk di Ujung Pandang. Penelitian Universitas Hasanuddin Ujung Pandang, 1982. Adam JMF.

4. EM Yunir, Waspadji S, Rahajeng E. The Pre-diabetic Epidemiological Study in Depok, West Java. Acta Med Indones-Indones J Intern Med 2009: 41: 181 - 185.

5. Suastika K, Dwipayana P, Saraswati IMR, Gotera W, Budhiarta AAG, Sutanegara IND, et al. An epidemiological study on obesty, glucose intolerance and metabolic syndrome in population of Bali, Indonesia. Diabetes.2010, 59(Suppl 1): A608

6. Adam FMS, Sanusi H, Adam JMF, Shyong TE. Prevalensi diabetes melitus and glukosa puasa terganggu pada masyarakat kelompok sosio-ekonomi menengah di makassar. Naskah Len- gkap Kongres Nasional Perkumpulan Endokrinolgi Indonesia (KONAS IX PERKENI) Manado 2012.

7. Harris MI. Undiagnosed NIDDM: clinical and public health issues. Diabetes Care 1993; 16; 642 - 652.

8. American Diabetes Association. Standards of medical care in diabetes 2010. Diabetes care; 33: S11 - S12

9. Leiter LA, Barr A, Lubin S, Ross SA, Tildesley HD, Fontaine N. Diabetes screening in Canada (DIASCAN) Study: prevalence of undiagnosed diabetes and glucose intolerance in family physician offices. Diabetes Care 2001; 24: 1038 - 1043.

10. Cogneau J, Balkau B, Weill A, Liard F, Simon D. Assessment of diabetes screening by general practitioners in France: the EPIDIA study. Diabet Med. 2006;23:803-807.

11. Welborn TA, Reid CM, Marriou G. Australian Diabetes Screening Study: impaired glucose tolerance and non-insulin dependent diabetes mellitus. Metabolism 1997; 46 (suppl 1): 35-39.

12. Ramachandran A, Snehalatha C, Vijay V, Colagiuri S. Detecting Undiagnosed Diabetes in Urban Asian Indians - Role of Opportunistic Screening. JAPI 2004; 52: 545-546.

13. Age-and sex-specific prevalence of diabetes and impaired glucose regulation in 13 European cohorts: DECODE Study Group. Diabetes Care. 2003 Jan; 26(1):61-9. 